\title{
sciendo DANGEROUS PHONES ARISING FROM THE WAVES DURING THE OCEANIC ROUTE SHIP
}

DOI 10.2478/ntpe-2018-0023

\author{
prof. dr hab. inż. Tadeusz Szelangiewicz \\ dr hab. inż. Katarzyna Żelazny, prof. AM \\ Maritime University of Szczecin, Poland
}

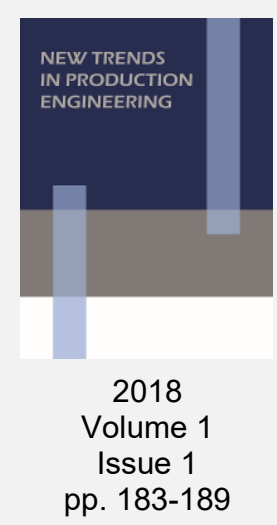

\begin{abstract}
Ocean routes are recommended for ships based on economic criteria. Under the influence of waves, during the cruise of the ship, dangerous phenomena are created, the intensity of which depends on the speed of the ship and its course in relation to the direction of the waves, the state of the sea, the size of the ship, the state of loading. Although weather services are known, waves parameters are not used to calculate the value of parameters that characterize dangerous phenomena. The article presents the most frequently analysed dangerous phenomena, how they are calculated, the criteria for their evaluation, and the results of calculations for the selected vessel.
\end{abstract}

Keywords: forecasting of shipping routes, irregular waves, dangerous phenomena when the ship is sailing at the waves

\section{INTRODUCTION}

One of the most important tasks that has a major impact on operating costs is the forecasting of an ocean shipping route when operating a transport ship.

Current forecasting of ocean shipping is conducted according to the following criteria (Wiśniewski, 1991):

- minimizing travel time,

- minimizing fuel consumption,

- minimizing fuel consumption at the assumed time of ship travel.

During a cruise on the ocean route, apart from additional resistance and drop in velocity, waves are also generated by dangerous phenomena that can cause safety hazards or lead to a sea crash. Hence, research is conducted to develop algorithms to calculate the parameters of dangerous phenomena, useful for use in programs predicting ocean shipping routes.

The article has been presented:

- most often considered dangerous phenomena occurring when the ship at the waves,

- criteria for assessing ship safety risks,

- results of calculation of dangerous parameters values for selected ship.

\section{FORECASTING OF SELECTED DANGEROUS PHENOMENA ARISING FROM WAVES}

When sailing the ship at the waves, the direct effect is:

- motions,

- and their derivatives: motions velocity and acceleration.

The secondary phenomena accompanying rocking are:

- flooding the deck,

- emergence of the propeller,

- worsening or loss of stability,

- additional dynamic loading of cargo and hull (local or global);

- deterioration of maneuverability. 
In each of these phenomena there are various situations or instances in which the safety of the ship may pose a threat. These phenomena can be described by different mathematical models. The more complete and detailed the description, the mathematical model is more complex and difficult to solve, especially for the irregular, random wave. Hence, at present, these phenomena are used to assess the safety of the ship while sailing at the waves, which, with sufficient accuracy, can be described by the simplest random mathematical models.

Typical phenomena are:

- rolling,

- pitching,

- vertical acceleration,

- transverse horizontal acceleration,

- flooding of the deck,

- slamming,

- emergence of the propeller.

These phenomena are also most often considered or recommended for the assessment of seakeeping of a ship or in determining the vessel's operating efficiency (Girtler et al., 1995, Lloyd, 1989, Mudronja et al., 2015, Szelangiewicz, 1999, Szelangiewicz, 2001).

\section{Motions of the ship on the wave}

Using the commonly used linear motions theory (Dudziak, 1988), under which, on a regular wave with given equation:

$$
\xi(t)=\xi_{A} \cos (k x-\omega t),
$$

motions on this wave have a figure:

$$
u=u_{A} \cos \left(-\omega_{E} t+\varepsilon_{u}\right),
$$

this random motions of the ship on an irregular waves can be simply determined by the knowledge of the amplitude characteristics of the motions on the regular wave and the spectral density function of the random wave energy. The variation of the ship's motions is then equal:

$$
D_{u u}\left(\beta_{W}, V\right)=\int_{0}^{\infty}\left[Y_{u \xi}\left(\omega_{E} / \beta_{W}, V\right)\right]^{2} S_{\xi \xi}\left(\omega_{E}\right) \mathrm{d} \omega_{E},
$$

where:

- $D_{u u}$ variance of ship motions $u, u=1,2, \ldots, 6$ (for $u=4$ rolling, $u=5$ pitching),

- $Y_{u \xi}$ amplitude transfer functions of ship motion $u$ on regular wave,

- $S_{\xi \xi}\left(\omega_{E}\right)$ function of the waves energy spectral density, the value of which depends mainly on the significant wave height $H_{s}$ and on period $T_{1}$,

- $\beta_{w}$ angle of wave effect acting on the ship,

- $\omega_{E}$ frequency of encounter of ship motions,

$$
\omega_{E}=\omega-k V \cos \beta_{W},
$$

- $\omega_{E}$ frequency of regular wave,

- $k$ wave number,

$$
k=\frac{\omega^{2}}{g} .
$$

The root of variance $D_{u u}$ is the average square deviation of the ship's motions in irregular wave, on the basis of which it is possible to calculate the statistical value of the random motions with the assumed probability of exaggeration, eg:

$$
\bar{u}_{A 1 / 3}=2,0 \sqrt{D_{u u}},
$$

$u_{A 1 / 3}$ - significant amplitude of motion $u$ (average motion $u$ amplitude of $1 / 3$ of the highest motion values).

The remaining phenomena, which arise when the ship sailing at the wave, can be made dependent on the motions of the ship and the method of calculating the parameters of these phenomena within the linear theory is carried out according to the algorithm described in formulas (3) and (6). 


\section{Acceleration ship on the wave}

The acceleration components of any point $P$ belonging to the ship under the linear motions theory are equal:

where:

$$
\begin{aligned}
& \left.a_{x P}=\ddot{X}_{G}-y_{P} \ddot{\Psi}+z_{P} \ddot{\Theta}\right) \\
& \left.a_{y P}=\ddot{Y}_{G}-z_{P} \ddot{\Phi}+x_{P} \ddot{\Psi}\right) \\
& \left.a_{z P}=\ddot{Z}_{G}+y_{P} \ddot{\Phi}-x_{P} \ddot{\Theta}\right),
\end{aligned}
$$

- $a_{x p}$ horizontal longitudinal acceleration,

- $a_{y p}$ transverse horizontal acceleration,

- $a_{z p}$ vertical acceleration,

- $\ddot{X}_{G}, \ddot{Y}_{G}, \ddot{Z}_{G}, \ddot{\Phi}, \ddot{\Theta}, \ddot{\Psi}$ acceleration from the motions, respectively: surge, sway, heave, roll, pitch, yaw,

- $x_{P}, y_{P}, z_{P}$ coordinates of point $P$ (Fig. 1) in the system related to the center of mass of the ship - Gxyz.

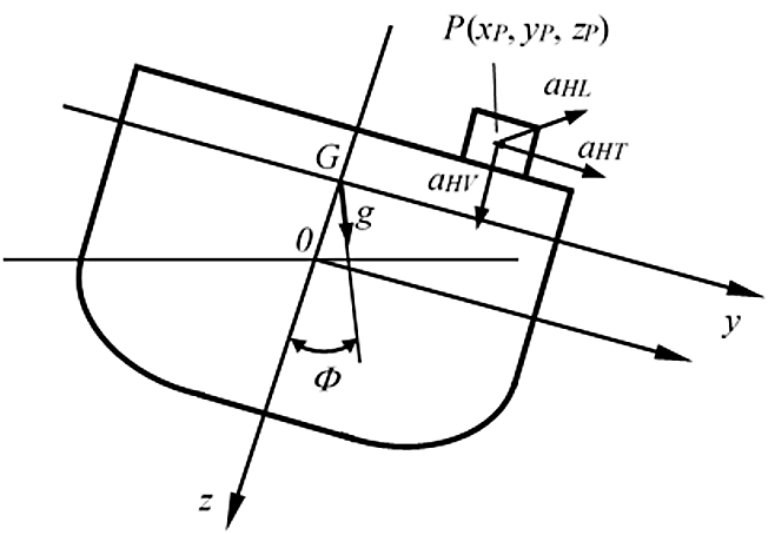

Fig. 1. Coefficients of mass forces in a coordinate system Gxyz.

Because acceleration from the motions of the ship is equal:

$$
\ddot{u}=-u_{A} \omega_{E}^{2} \cos \left(-\omega_{E} t+\varepsilon_{u}\right)=-\omega_{E}^{2} \cdot Y_{u \xi} \cdot \xi(t),
$$

this is the amplitude characteristics of the mass force coefficients (their return is in line with the mass return) are as follows:

$$
\begin{gathered}
Y_{A H L}\left(i \omega_{E}\right)=\omega_{E}^{2}\left[Y_{x \xi}\left(i \omega_{E}\right)+\left(z_{P} k-\frac{\omega^{2}}{\omega_{E}^{2}}\right) Y_{\Theta \alpha}\left(i \omega_{E}\right)-y_{P} k Y_{\Psi \alpha}\left(i \omega_{E}\right)\right] \\
Y_{A H T}\left(i \omega_{E}\right)=\omega_{E}^{2}\left[Y_{y \xi}\left(i \omega_{E}\right)-\left(z_{P} k-\frac{\omega^{2}}{\omega_{E}^{2}}\right) Y_{\Phi \alpha}\left(i \omega_{E}\right)+x_{P} k Y_{\Psi \alpha}\left(i \omega_{E}\right)\right] \\
Y_{A V}\left(i \omega_{E}\right)=\omega_{E}^{2}\left[Y_{z \xi}\left(i \omega_{E}\right)+y_{P} k Y_{\Theta \alpha}\left(i \omega_{E}\right)-x_{P} k Y_{\Theta \alpha}\left(i \omega_{E}\right)\right]+g .
\end{gathered}
$$

Using the formulas (3) and (6), significant amplitudes of mass force coefficients are calculated: $\bar{a}_{A H L 1 / 3}, \bar{a}_{A H T 1 / 3}$ and $\bar{a}_{A V 1 / 3}$.

\section{Relative motion of the ship on the wave}

When the ship motions on the wave, its motion (movement) can be determined relative to the surface of the waves. The resulting relative movement is decisive for such phenomena as deck flooding, emergence of the propeller (Fig. 2) or slamming (in case of slamming, the relative vertical velocity of the ship (Fig. 3 ) is the probability of a slamming occur).

The vertical, absolute displacement of the ship resulting from the ship motions is equal to:

$$
S_{z P}=Z_{G}+y_{P} \Phi-z_{P} \Theta,
$$

whereas the relative motion of the ship:

$$
R_{z P}=S_{z P}-\xi(t)
$$

where $\zeta(t)$ is the wave profile described by equation (1). 

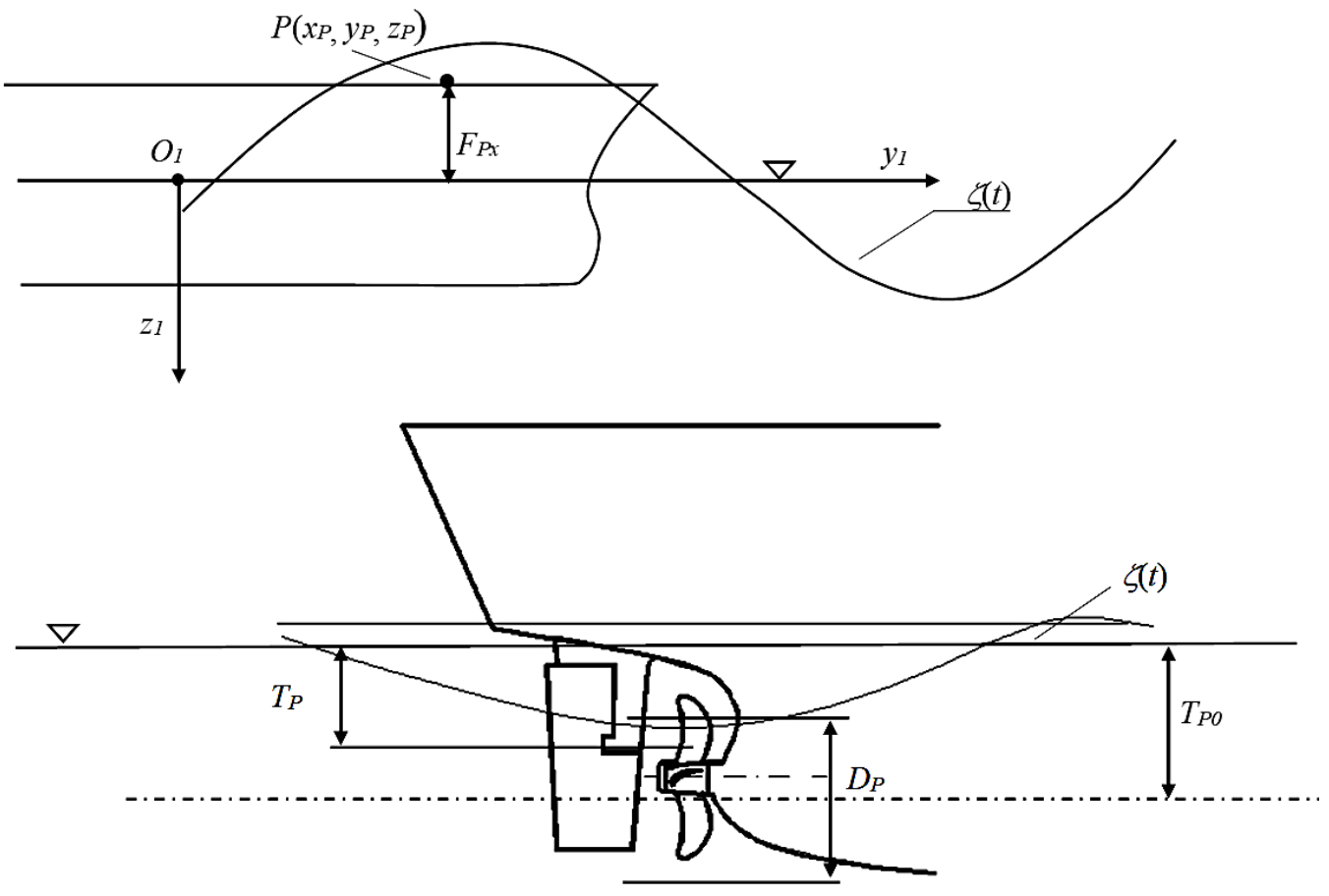

Fig. 2. Effect of relative motion on deck flooding and propeller emergence.

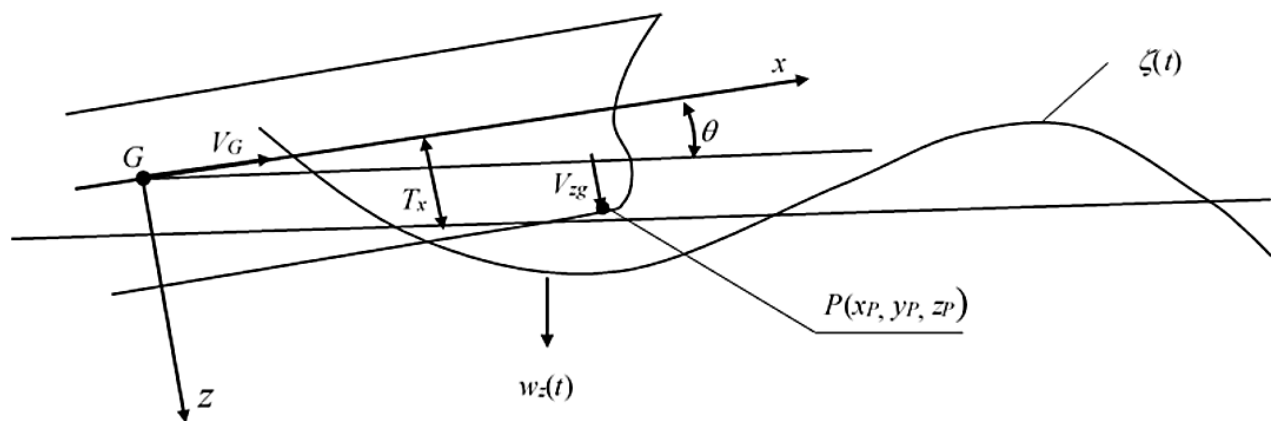

Fig. 3. Emergence of the bow and the relative velocity of entering the bow into the water.

As in the case of accelerations, the equations $(10) \div(11)$ calculate the amplitude characteristics of the relative motion and relative velocity and then the variances. Since deck flooding, propeller emergence and slamming are not continuous phenomena and occur only in certain situations, then for these phenomena, the probability is calculated (Szelangiewicz and Żelazny, 2013):

- relative movement exceeds the freeboard height $F_{P_{x}}$ (for flooding the deck, Fig. 2),

- relative movement exceeds the depth of the screw point $T_{P}$ (for the ascent of the screw, Fig. 2),

- relative motion will exceed the draught of the bow $T_{x}$ and at the same time the relative velocity of the bow to the water $V_{P Z P}$, Fig. 3, will exceed the critical velocity $V_{k r}=0,093 \sqrt{g L}$ (for slamming).

For these phenomena, the number and probability of their occurrences are as follows:

$$
N_{Z}=\frac{360 \cdot p_{z}}{\bar{T}_{u}}
$$

where:

- $N_{Z}$ number of deck flooding per hour, propeller emergence or slamming,

- $\bar{T}_{u}$ average motions period,

- $p_{z}$ probability of local relative motion exceeding the draught, deck submergence or propeller emergence. 


\section{CRITERIA FOR ASSESSING THE SEAKEEPING PROPERTIES OF THE SHIP}

On the basis of long-term observations and experience, the permissible values of motions of the ship and the accompanying phenomena above which the safety of the ship, crew or equipment on board is at risk equates to the limitation of the transport mission. The level of limit values is also dependent on the type and size of the ship. A summary of the criteria proposed by various researchers for selected seakeeping is provided in (Ghaemi and Olszewski, 2017, Karppinen, 1987 and Lloyd, 1989).

Table 1.

Criteria for selected seakeeping.

\begin{tabular}{|c|c|c|c|}
\hline & $\begin{array}{c}\text { Merchant } \\
\text { vessels }\end{array}$ & Warships & $\begin{array}{c}\text { Fast small } \\
\text { units }\end{array}$ \\
\hline Vertical accelerations at the bow (RMSD) & $\begin{array}{c}0.275 \mathrm{~g} \text { small } \\
0.1 \mathrm{~g} \text { large }\end{array}$ & $0.275 \mathrm{~g}$ & $0.65 \mathrm{~g}$ \\
\hline Vertical acceleration in the bridge (RMSD) & $0.15 \mathrm{~g}$ & $0.2 \mathrm{~g}$ & $0.275 \mathrm{~g}$ \\
\hline Horizontal lateral acceleration in the bridge (RMSD) & $0.12 \mathrm{~g}$ & $0.1 \mathrm{~g}$ & $0.1 \mathrm{~g}$ \\
\hline Rolling (RMSD) & $6.0^{\circ}$ & $4.0^{\circ}$ & $4.0^{\circ}$ \\
\hline $\begin{array}{l}\text { Slamming } \\
\text { - probability of occurrence for } 100 \text { waves } \\
\text { - number per hour }\end{array}$ & $\begin{array}{c}0.03 \text { small } \\
0.01 \text { large } \\
20\end{array}$ & 0.03 & 0.03 \\
\hline $\begin{array}{l}\text { Flooding the deck } \\
\text { - probability of occurrence for } 100 \text { waves } \\
\text { - number per hour }\end{array}$ & $\begin{array}{c}0.05 \\
30\end{array}$ & 0.05 & 0.05 \\
\hline
\end{tabular}

Source: Karppinen, 1987

\section{CALCULATION OF DANGEROUS PARAMETER VALUES FOR AN EXEMPLARY SHIP}

Calculations of the parameters of the dangerous phenomena listed at the beginning of the article were made for an exemplary ship, for different speeds and course rates of the ship relative to the direction of waves and for different states of the sea. Calculation of parameters of seakeeping was made for the points shown in Fig. 4.

The influence of the $V$ speed of the ship and the $\beta_{W}$ course with respect to the wave on some seakeeping of the irregular wave with the corresponding criterion for the given phenomenon is presented in Figure 5. In this figure, two levels of the criteria in the form of fields of specified colors are indicated.

Wave: $H_{S}=8.5 \mathrm{~m} ; T_{1}=10.1 \mathrm{~s} ; \mu=0^{\circ}$

Ship: $V=10 \mathrm{kn} ; \psi=45^{\circ}$

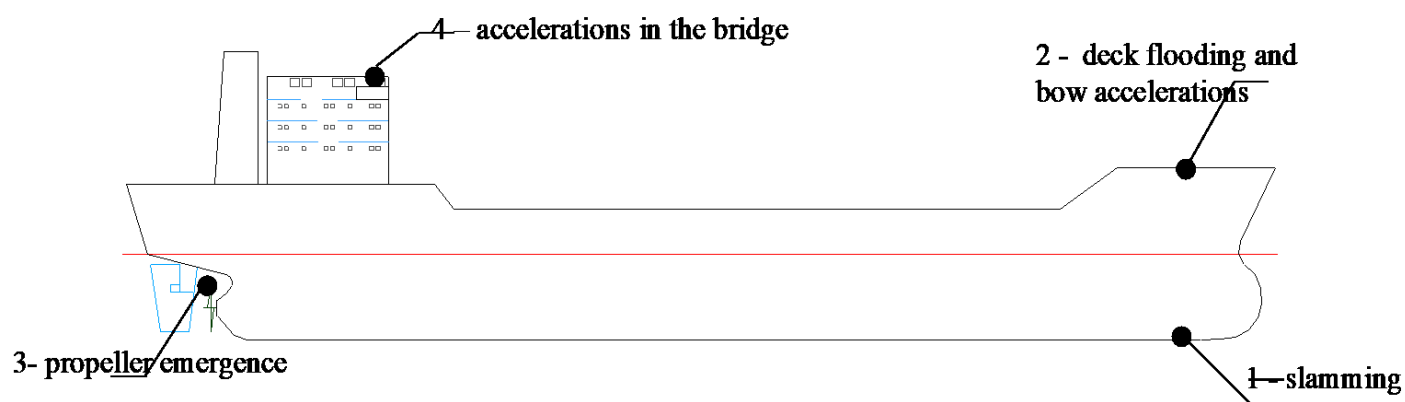

Fig. 4. Points for which seakeeping parameters have been calculated 


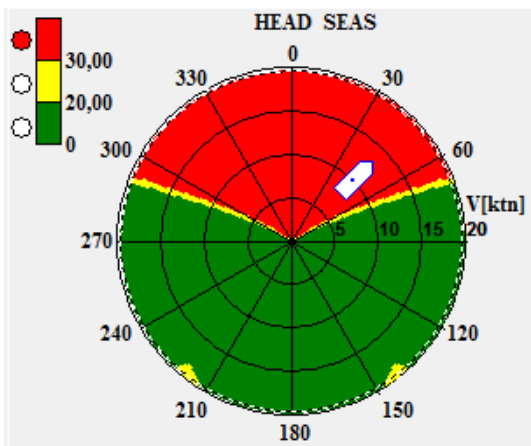

Flooding of the deck

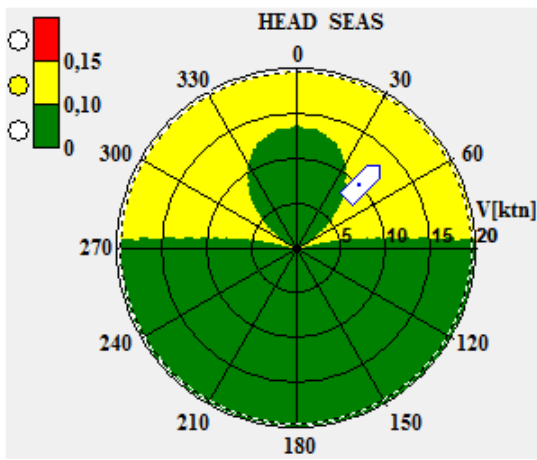

Vertical acceleration in the bridge

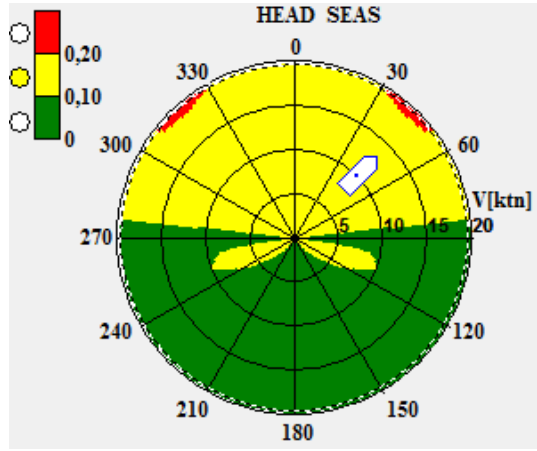

Vertical acceleration at the bow

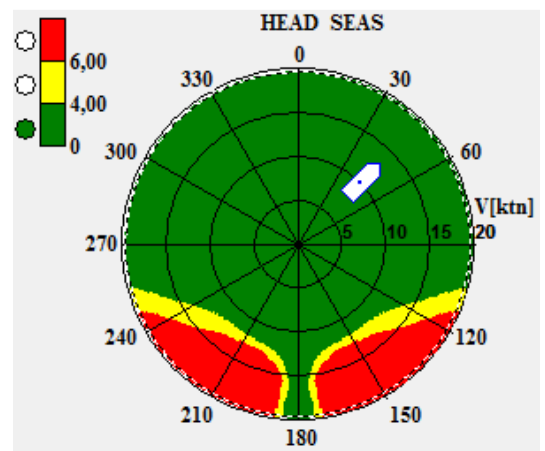

Rolling

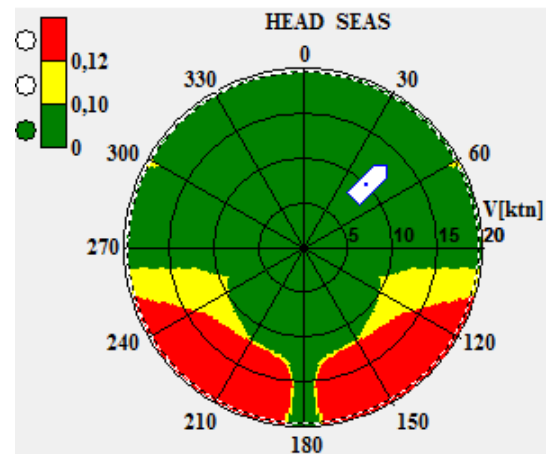

Horizontal lateral acceleration in the bridge

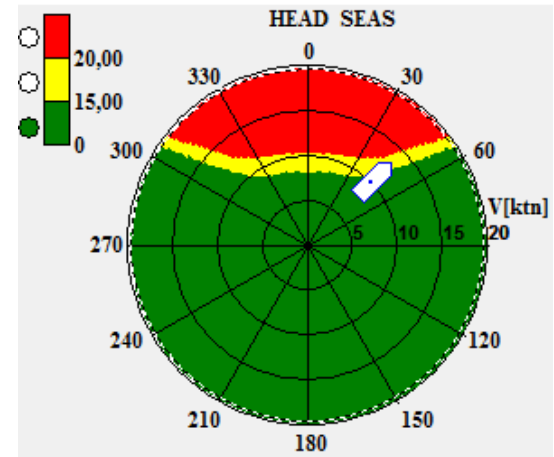

Slamming

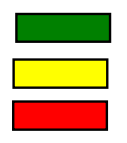

- the ship sails securely

- warning about dangers (lower limit of the relevant criterion exceeded)

- threat to the safety of the ship (upper limit of the relevant criterion exceeded)

Fig. 5. Effect of course on wave and speed of ship K2 on selected seakeeping.

\section{CONCLUSIONS}

- For calculation of the parameters of dangerous motions phenomena are necessary frequency characteristics (amplitude and phase) rocking the ship on a regular wave. These characteristics depend on the speed of the ship and its loading (draught).

- Based on these characteristics and parameters of the irregular wave, the parameters of the dangerous phenomena that may occur during an ocean line cruise can be calculated.

- The intensity of these phenomena depends not only on the wave parameters, but also on the operating parameters of the ship: velocity $V$ and course relative to the wave direction. The computed polar charts show examples of situations and opportunities for correcting, for example, the course to avoid the risk of waves. 


\section{REFERENCES}

Dudziak, J. (1988). Teoria okrętu. Gdańsk: Wydawnictwo Morskie.

Ghaemi, M. H. and Olszewski, H. (2017). Total ship operability -review, concept and criteria. Polish maritime research, 24(1), pp. 74-81.

Girtler, J., Kitowski, Z. and Kuriata, A. (1995). Bezpieczeństwo okrętu na morzu. Warszawa: Wydawnictwo Komunikacji i Łączności.

Karppinen, T. (1987). Criteria for Seakeeping Performance Predctions. Helsingfors: Technical Research Centre of Finland.

Lloyd, A.R.J.M. (1989). Seakeeping: Ship Behaviour in Rough Weather. Chichester, England: Ellis Horwood Series in Marine Technology.

Mudronja, L., Vidan, P. and Parunov, J. (2015). Review of seakeeping criteria for container ship sustainable speed calculation in rough weather. Maritime technology and engineering, 1 \& 2, pp. 1059-1064.

Szelangiewicz, T. (1999). Bezpieczeństwo statku podczas pływania w warunkach sztormowych. In: Konferencja: Problemy eksploatacji statków morskich i śródlądowych oraz urządzeń portowych, EXPLO-SHIP'99. Szczecin: Wyższa Szkoła Morska w Szczecinie, 2, pp. 185192.

Szelangiewicz, T. (2001). Estimation operational effectiveness of ship sails in waves. In: 14th International Conference on Hydrodynamics in Ship Design. Szczecin: Technical University of Szczecin, pp. 324-334.

Szelangiewicz, T. and Żelazny, K. (2013). The influence of the propeller emergence on the torque during sailing of a ship on a regular wave. Scientific Journals of The Maritime University of Szczecin-Zeszyty Naukowe Akademii Morskiej w Szczecinie, 35(107), pp. 138-143.

Wiśniewski, B. (1991). Problemy wyboru drogi morskiej. Gdańsk: Wydawnictwo Morskie. 